\title{
Experimental and numerical study on the performance of different fire ventilation systems
}

\author{
Marius Dorin Lulea ${ }^{1}$
}

${ }^{1}$ doctoral Candidate at the Technical University of Civil Engineering Bucharest, Faculty of Building Services Engineering, street bdul. Pache Protopopescu, no. 66, Bucharest, zip code 021414, Romania phone 0040764701500 ,

E-mail: luleamariusdorin@gmail.com

\begin{abstract}
In the fire safety design of buildings, it is common practice to consider a smoke and heat exhaust ventilation system. The choice is made between either natural ventilation or a mechanical ventilation system. In case of a fire, the main requirement for building designers is to save users. For the safety of users during a fire, low temperatures, high oxygen concentration and good visibility for a certain period must be ensured.

Three different cases of ventilation in case of fire were analyzed in this study: mechanical ventilation (CASE1) and natural ventilation (CASE2- wall hatches and CASE3- roof hatches). The results of an experimental study were used to validate a numerical model (CASEO-no ventilation system) using FDS software. The action of the fire in a room with an area of $18(\mathrm{~m} 2)$ has been studied.

Indoor temperatures, oxygen concentration and visibility are determined and used to establish the performance of different ventilation system. The three parameters play an important role in assessing the environmental conditions necessary to save users.

The study shows that natural or mechanical ventilation in case of fire considerably improves the evacuation conditions, saving users' lives. Both types of ventilation ensure good performance in the situation of a correct dimensioning and designs.
\end{abstract}

Key words: CFD, FDS, fire, real- scale fire tests, ventilation

\section{Introduction}

Design of buildings for fire action has become a common concern. Designing buildings for fire action involves identifying the best solutions that allow saving users, ensuring firefighters' intervention, preventing the collapse of buildings, limiting the spread of fire, limiting the damage of a fire [1].

Globally, the number of victims resulting from the action of the fire exceeds any other risk to which a building is subjected during its lifetime [2]. Most victims of a fire occur because of intoxication with smoke, hot gases, and pollutants [3].

The main parameter used to define the action of a fire is the indoor temperature. The concentration of oxygen, the concentration of toxic gases and the visibility are also important. 
Modeling the action of fires on constructions can be done by simple mathematical models, zonal models, or complex field models [4]. Mathematical models are the most used due to the low computational resources required. As the computational technique develops, the use of complex field models in fire modeling becomes relevant. Field models allow to simulate the action of fires close to reality but require high computing resources.

Ventilation is a method of protecting the space in case of fire. The purpose of ventilation is to maintain optimal conditions for the survival of users for a certain period (low temperatures, high oxygen concentration, low harmful gases concentration and good visibility).

Ventilation in case of fire can be mechanical ventilation or natural ventilation. Natural ventilation involves the automatic and manual opening of the windows/hatches from the burned space to evacuate the defective air. Mechanical ventilation involves the use of an electric fan to extract foul air.

In this study, three cases have been simulated with different smoke and hot air ventilation system. Predictions of temperature, visibility and oxygen concentration are presented. The fire dynamics simulator (FDS) code, based on the concept of large eddy simulation, is adopted in the present simulation for good the fire modeling performance [5] [6]. No ventilation in room is used as a benchmark.

\section{Materials and Methods}

The test results are designated as reference for calculation models validation [7].

A real-scale experimental stand bas been used in the present research. The fire action was simulated with the help of a burner that uses LPG gas as a fuel.

The interior temperatures were recorded during the experiment.

The main components of the experimental stand are the construction, the combustion plant of the fuel, the installation of the exhaust air, the slit that provides the fresh air supply and the temperature sensor.

\subsection{Experimental device}

The experimental stand is a realistic room with an area of $18\left(\mathrm{~m}^{2}\right)(\mathbf{F i g}$. 1). The interior dimensions are $3(\mathrm{~m}) \times 6(\mathrm{~m})$ ground surface, with a ceiling height of $2.7(\mathrm{~m})$.

The test room consists in four exterior walls made of mineral wool panels which have a thickness of $0.10(\mathrm{~m})$.

In the exterior walls there was provided a door $(0.9(\mathrm{~m}) \times 2.1(\mathrm{~m}))$, a window with an incombustible metal frame $(0.6(\mathrm{~m}) \times 1.2(\mathrm{~m}))$, air outlet $(0.25(\mathrm{~m}) \times 0.25(\mathrm{~m}))$ and an air inlet $(0.4(\mathrm{~m}) \times 0.1(\mathrm{~m}))$. 
Experimental and numerical study on the performance of different fire ventilation systems

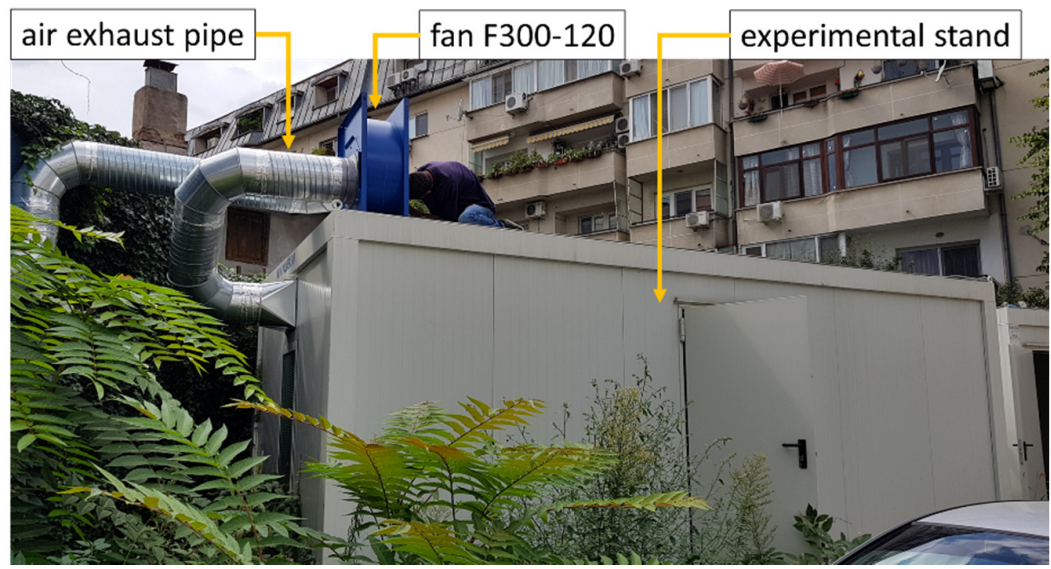

Fig. 1. Image of the experimental stand.

The experimental stand was made of incombustible materials that provide a fire resistance of $180(\mathrm{~min})$ for walls, floor, and roof and $90(\mathrm{~min})$ for the door.

\subsection{Burner}

LPG gas was used as a fuel to simulate the fire. Gas was used because the combustion is controlled, unlike if solid or liquid fuels were used.

The installation consists of a burner, a metal supply line, and a fuel tank (Fig. 2). The combustion installation had two burners with a cumulative area of $0.25(\mathrm{~m}) \times 0.6$ $(m)$. The gas supply was made from a $60(l)$ tank mounted outside the experimental stand. With the help of a gas pressure regulator and a service tap, the flue gas flow was adjusted.

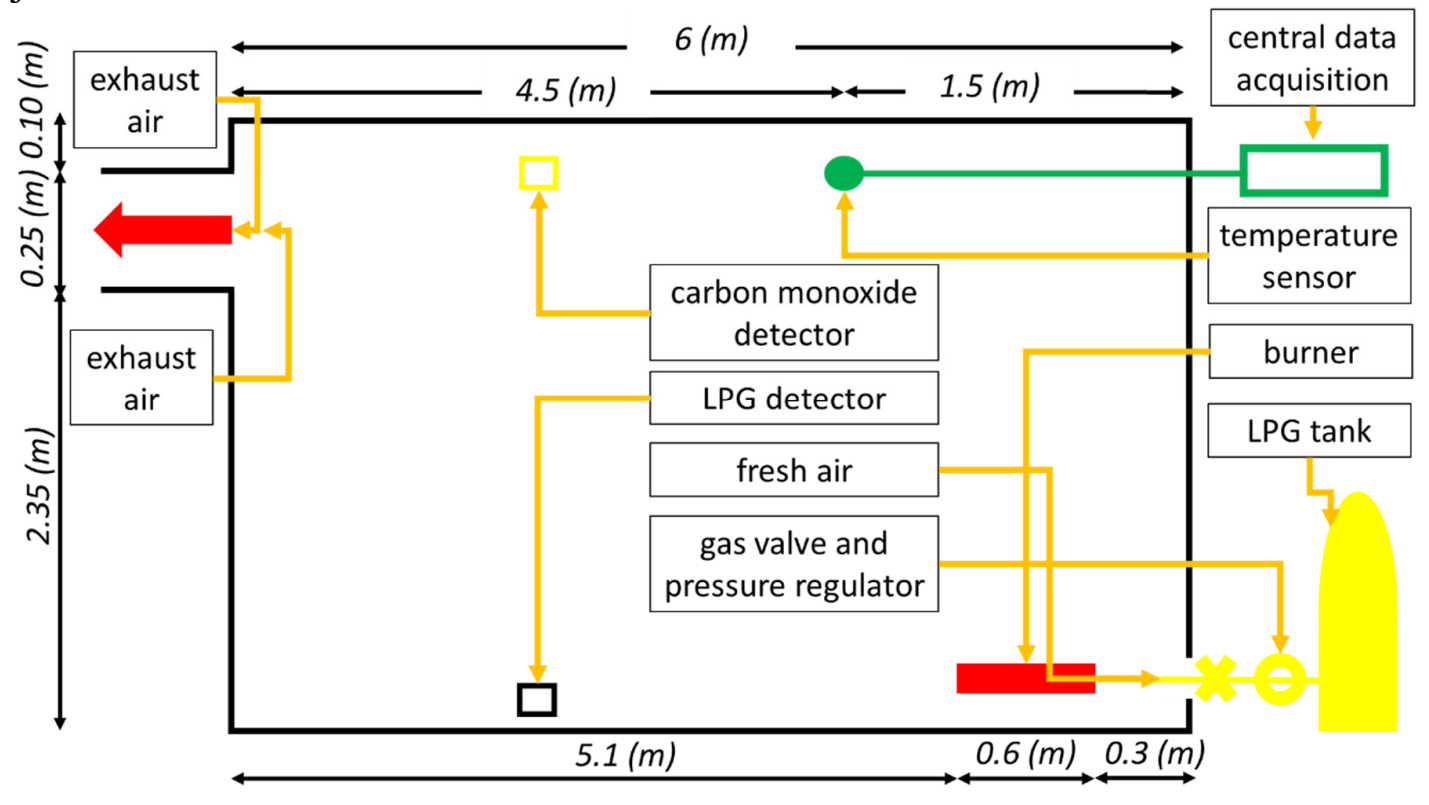

Fig. 2. Experimental stand sketch. 
Near the burner was provided the air inlet slot. This slot provides the fresh air charged with the oxygen needed to burn.

At the bottom of the stand there is an LPG detector. It has the role of detecting the unburned gas and is provided for the safety of the experiment. At the top of the stand was provided a carbon monoxide detector for the situation in which the combustion would not be complete.

\subsection{Measurement of temperature}

The only parameter recorded was the indoor air temperature in point S1. One sensor was placed at the centerline of the ceiling (Fig. 2).

A thermocouple type $\mathrm{K}$ sensor was used. Data recording was done with an ALMEMO710 data acquisition plant. This type of sensor is recommended for positive temperatures lower than $1000\left({ }^{\circ} \mathrm{C}\right)$. The measurement error is $0.1\left({ }^{\circ} \mathrm{C}\right)$.

The duration of the experiment has been $760(s)$ - the tests has been stopped when a $90\left({ }^{\circ} \mathrm{C}\right)$ temperature was reached in the room. The evolution of indoor temperatures throughout the event was recorded. The data recording step was set at $5(s)$.

For safety, a sensor for detecting unburned LPG was mounted on the bottom of the camera and a sensor for detecting carbon monoxide was mounted on the top of the camera.

\section{Modelling and calibration}

There are three type of methods for modelling the reaction to fire of buildings: simplified mathematical models [8], zonal models who divide the burnt space into two zones characterized by an average temperature [9], computational fluid dynamics (CFD) models that allow the simulation of the fire closer to the reality [4].

Full-scale complementary computational fluid dynamic (CFD) simulations are carried out with fire dynamics simulator FDS. An approximate form of Navier-Stokes equations appropriate for low Mach number applications is used [10]. To handle subgrid scale convective motion, Large Eddy Simulation (LES) technique is adopted [11].

The numerical model assumes knowledge as input data of the geometrical characteristics of the room, the material characteristics, the way in which the combustion is modeled, the size of the discretization network.

\subsection{Geometric model and mesh}

The dimensions of the room were determined by direct measurement (Fig. 3). The room has the interior dimensions of $6 \times 3 \times 2.7\left(\mathrm{~m}^{3}\right)$. The wall thickness is $0.10(\mathrm{~m})$.

The burner $\left(0.25 \times 0.6\left(\mathrm{~m}^{2}\right)\right)$, air outlet $\left(0.25 \times 0.25\left(\mathrm{~m}^{2}\right)\right)$ and air inlet $\left(0.4 \times 0.1\left(\mathrm{~m}^{2}\right)\right)$ are placed in the same position as in the experiment. The dimensions were determined by direct measurements. 
Experimental and numerical study on the performance of different fire ventilation systems

Reasonable extension of the computational domain has been proved to be necessary to acquire accurate results. Therefore, some additional computational regions are added near the wall $(0.5 \mathrm{~m})$.
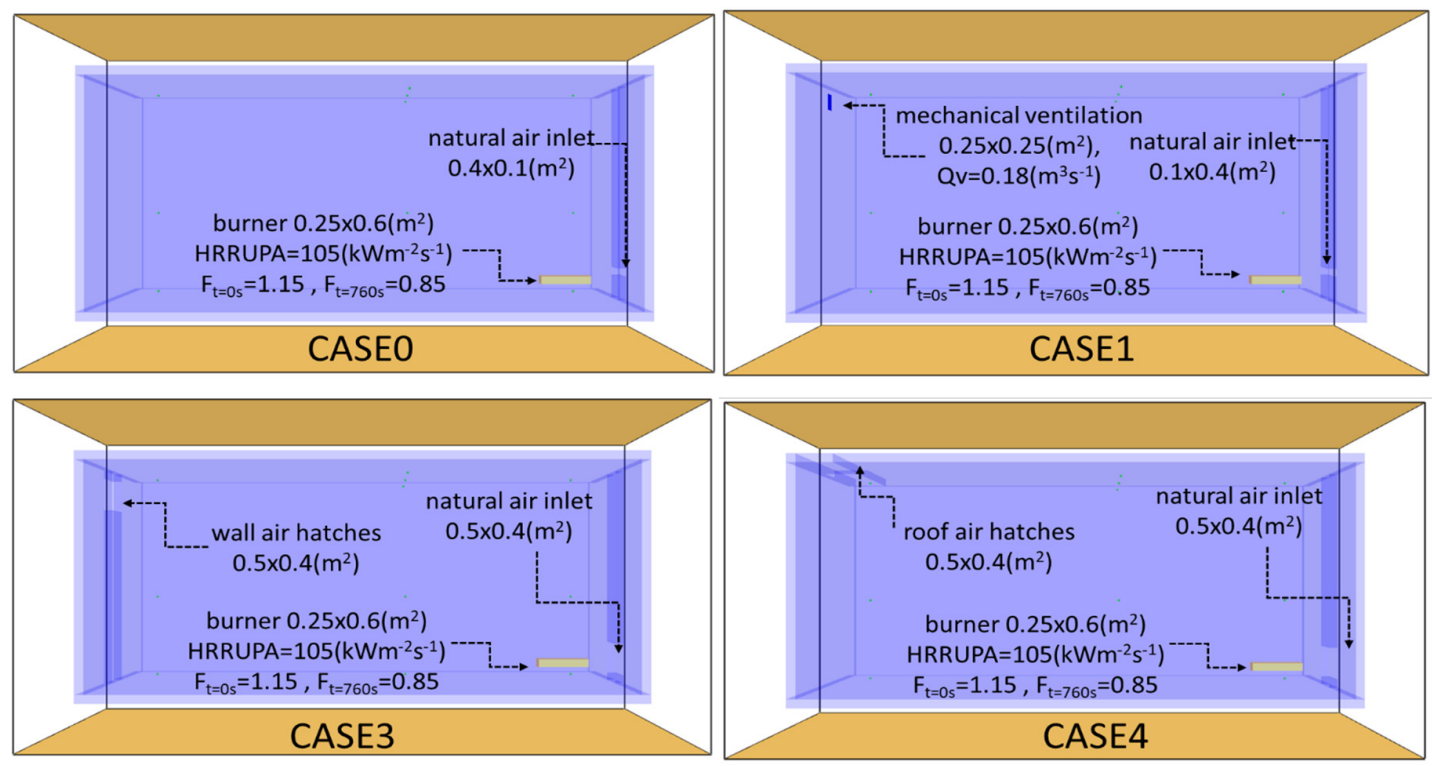

Fig. 3. Graphical representation of the model.

Details such as the existence of the door, windows, various interior objects such as the water supply pipe, sprinklers, wires of temperature sensors, joints between the panels were not reproduced.

The grid size is an important factor to be considered. To establish the mesh, several different mesh sizes ranging from $0.025(\mathrm{~m})$ to $0.25(\mathrm{~m})$ are chosen for comparison. Two criteria were considered to determine the optimal mesh: computation time and standard deviation. Fig. 4 shows temperature distribution in point S1 of the three simulation with three different dimensions of the discretization network.

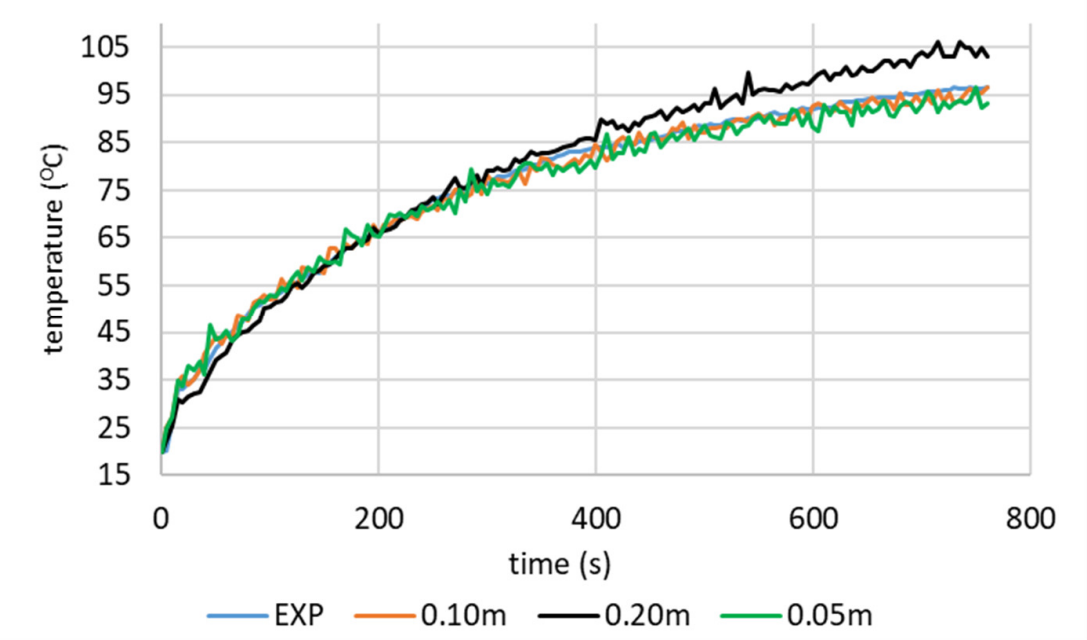

Fig. 4. Temperature evolution chart at different mesh, point S1. 
The computer could not operate the calculation for network dimensions less than $0.05(\mathrm{~m})$, for $0.05(\mathrm{~m})$ a single run lasted about $120(\mathrm{~h})$. A grid size of $0.1(\mathrm{~m})$ was chosen and it offers results very close to reality, with an error of only $2.1\left({ }^{\circ} \mathrm{C}\right)$.

Table 1 .

\section{Calculation time and standard mean deviation at different values of mesh dimensions}

\begin{tabular}{|l|l|l|}
\hline $\begin{array}{l}\text { Grid Dimension } \\
(\mathbf{m} \times \mathbf{m} \times \mathbf{~ m})\end{array}$ & $\begin{array}{l}\text { Calculation time } \\
(\mathbf{h})\end{array}$ & $\begin{array}{l}\sigma_{\text {Grr }} \\
\left({ }^{\mathbf{O}} \mathbf{C}\right)\end{array}$ \\
\hline $0.25 \mathrm{~m} \times 0.25 \mathrm{~m} \times 0.25 \mathrm{~m}$ & $0.5 \mathrm{~h}$ & 21.0 \\
\hline $0.20 \mathrm{~m} \times 0.20 \mathrm{~m} \times 0.20 \mathrm{~m}$ & $1 \mathrm{~h}$ & 19.8 \\
\hline $0.15 \mathrm{~m} \times 0,15 \mathrm{~m} \times 0,15 \mathrm{~m}$ & $2 \mathrm{~h}$ & 12.8 \\
\hline $0.10 \mathrm{~m} \times 0.10 \mathrm{~m} \times 0.10 \mathrm{~m}$ & $7 \mathrm{~h}$ & 2.1 \\
\hline $0.05 \mathrm{~m} \times 0.05 \mathrm{~m} \times 0.05 \mathrm{~m}$ & $120 \mathrm{~h}$ & 4.8 \\
\hline
\end{tabular}

\subsection{Material characteristics of the walls}

The materials from which the walls and floors are made are important for the calculation. The main material characteristics important for numerical analysis are: (a) the density $\left(\rho=120\left(\mathrm{~kg} / \mathrm{m}^{3}\right)\right)$, (b) the thermal conductivity ( $\lambda$ eqv $(\mathrm{W} / \mathrm{m} . \mathrm{K})$-determined), (c) the lower calorific value $(q i=0(M J / k g))$ and $(\mathrm{d})$ the thermal capacity $(c p=0.840$ $(\mathrm{kJ} / \mathrm{kg} . \mathrm{K}))$.

All characteristics were taken from the product sheet except the thermal conductivity. It was necessary to determine an equivalent thermal conductivity considering the differences between the real situation and the one in the model (the window and the door are not found in the calculation model) as well as the need to correct the value in the data sheet with the losses through the thermal bridges (intensified heat losses through the joints of the panels, in the area of the door and window, the joint between the walls and floors).

Several calculations were iterated at different values of thermal conductivity. The value of the thermal conductivity that showed the minimum average deviation $\left(\sigma_{\operatorname{Err}}\left({ }^{\circ} \mathrm{C}\right)\right)$ was chosen.

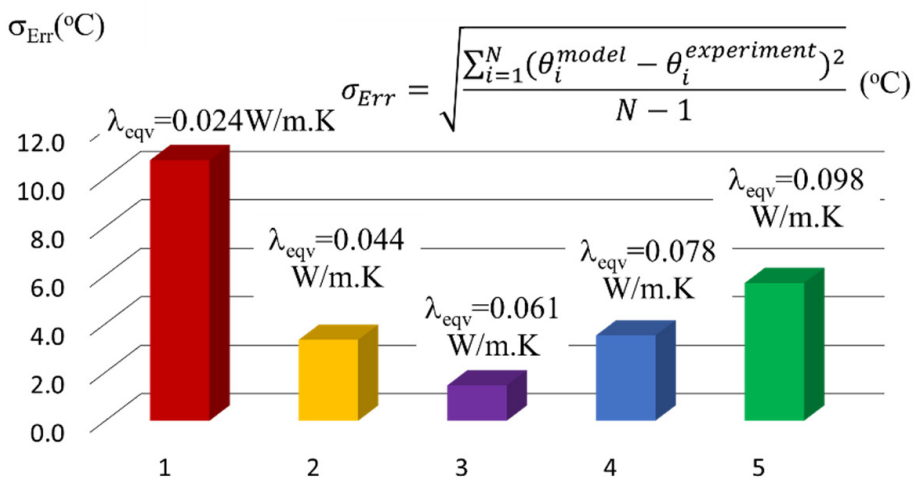

Fig. 5. $\sigma_{E r r}\left({ }^{\circ} C\right)$ for different values of $\lambda e q v(W / m . K)$ 
Experimental and numerical study on the performance of different fire ventilation systems

The equivalent thermal conductivity of the walls and floors has been set at $\lambda e q v=0.061\left({ }^{\circ} \mathrm{C}\right)$ with $\sigma_{E r r}=1.5\left({ }^{\circ} \mathrm{C}\right)$.

\subsection{Burner modeling}

The correct modeling of the fire source is necessary because this influences the obtained results [12].

A fire source is placed at $0.3(\mathrm{~m})$ from the outer wall. Its heat release rate is determined by the fire source area and heat release rate per unit area.

LPG gas from the cylinder was used during the experiment. Gas has the advantage of controlled combustion over solid fuels, with clear chemical and physical equations that are easy to model.

The total amount of gas consumed by combustion was determined by measuring the weight of the cylinder before and after the experiment: $M_{i}=0.315(\mathrm{~kg})$.

Knowing the lower calorific value of the LPG gas, $Q i\left(M_{J g^{-1}}\right)$, it was possible to determine the total amount of heat resulting from combustion [13], according to the equation $H R R=Q_{i} M_{i}(M J)(1)$ :

$$
H R R=Q_{i} M_{i}(M J)
$$

FDS allows fire modeling using HRRPUA (heat release rate per unit area). The surface of the burner is the same as in the experiment: $0.25 \times 0.60\left(\mathrm{~m}^{2}\right)$.

The amount of fuel burned is not constant during the experiment because of the decrease of pressure in cylinder: HRRPUA $=105\left(\mathrm{kWm}^{-2} \mathrm{~s}^{-1}\right), F_{t=O(s)}=1.15, F_{t=760(s)}=0.85$. The decrease curve was determined by repeated simulations.

\section{Results and discussion}

This study analyzes three possible cases of ventilation(CASE1, CASE2, CASE3) and compares them with the situation in which the space does not have any ventilation system in case of fire $(C A S E O)$ :

$C A S E 0$ : the room does not have a mechanical or natural ventilation system in case of fire;

CASE1: the room has a mechanical ventilation system for extracting hot air; the hot air extraction flow is $Q_{v}=0.18\left(\mathrm{~m}^{3} / \mathrm{s}\right)$; the air supply for compensation is made naturally through a slit located at the bottom of the outer wall: $0.10(\mathrm{~m}) \times(0.40(\mathrm{~m})$;

CASE2: the hot air is natural evacuated through a wall smoke hatches: $0.5(\mathrm{~m}) x$ $0.4(\mathrm{~m})$; the air supply for compensation is made naturally through a slit located at the bottom of the outer wall: $0.50(\mathrm{~m}) \times 0.40(\mathrm{~m})$;

CASE3: the evacuation of hot air is done natural through roof smoke hatches: $0.5(\mathrm{~m}) \times 0.4(\mathrm{~m})$.

The three cases take into account the recommendations of the current technical regulations [14].

Through this study we try to analyze which ventilation system has a higher performance. 
Three main parameters will be followed: indoor temperature, visibility and oxygen concentration at point $\mathrm{S} 1$.

\subsection{Temperature distribution}

In the temperature evolution chart (Fig. 6) it can be observed that all three situation smoke and hot air ventilation systems have similar performance. Indoor temperatures drop at point $S 1$ from almost $100\left({ }^{\circ} \mathrm{C}\right)$-CASE0 to about $60\left({ }^{\circ} \mathrm{C}\right)-\mathrm{CASE}$, $C A S E 2$, CASE3, proving that the performance of the ventilation system is high in all three cases.

Mechanical smoke and hot air ventilation lead to better ventilation in the initial stages of the fire $(C A S E 1)$, when hot air velocities are low due to low temperatures for $C A S E 2$ and $C A S E 3$. As the fire continues, indoor temperatures rise and air velocity increases through the wall or roof smoke hatches (CASE2, CASE3) and natural ventilation was done at a flow rates almost equal to mechanical ventilation.

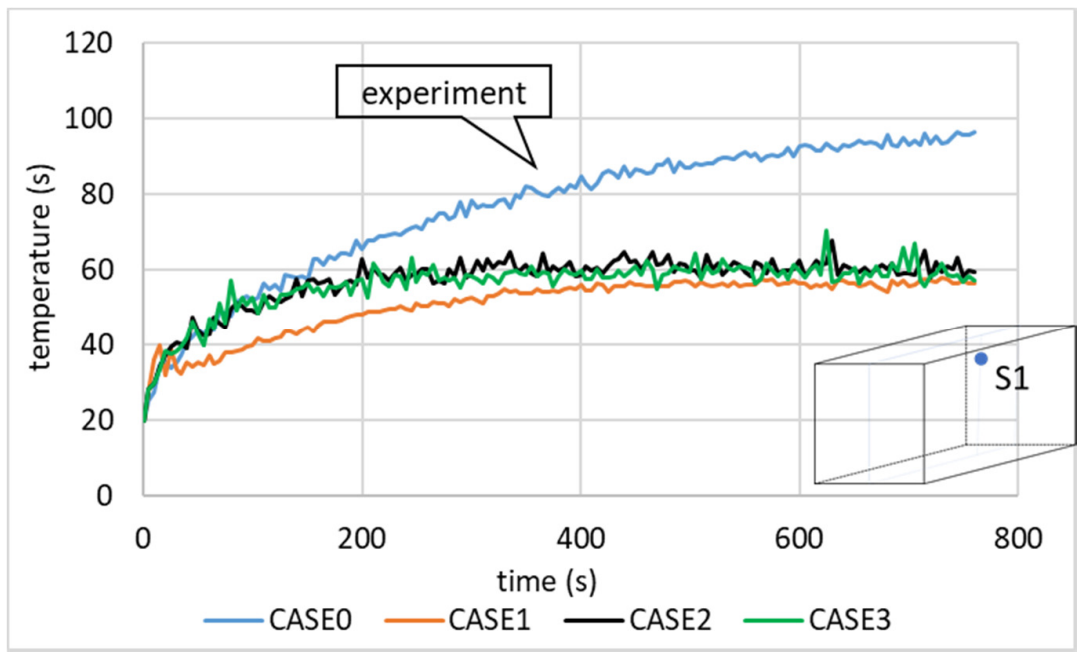

Fig. 6. Temperature evolution chart, point S1.

Fig. 6 shows a rapid stabilization of the temperature curve close to $60\left({ }^{\circ} \mathrm{C}\right)$. This is because a balance is struck between the amount of heat introduced into the room by the burning of gas and the loss of energy through the walls and the ventilation system.

The current regulations establish a correlation between the flow of hot exhaust air and the surface of the fan-protected space. It follows from the chart below that a correlation between the extraction flow and the thermal load, i.e. the amount of heat resulting from the combustion of combustible materials in the room, would be more appropriate.

Fig. 7 shows that in all cases the hot air rises to the top of the room from where it is evacuated to the outside through the mechanical ventilation system or through wall or roof hatches. In the case of mechanical ventilation, a destratification of the air can be observed and the hot air has a controlled circulation. It can be seen that cold air enters 
Experimental and numerical study on the performance of different fire ventilation systems through the slit situated at the bottom of the outer wall. As shown in the figure, temperatures near the fire source are much high.

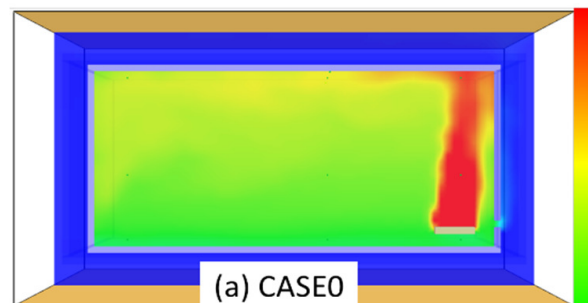

(a) CASEO

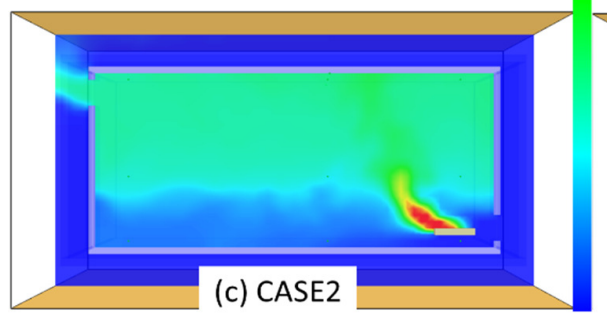

Fig. 7 Temperature at $t=760(s), y=2.1(m)$
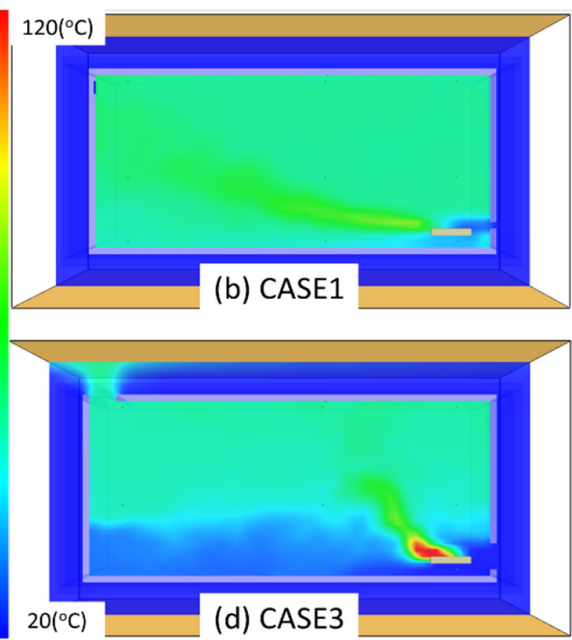

(d) CASE3

It can be seen that the temperatures at different points in the same horizontal plane are approximately equal and decrease as the horizontal plane is closer to the floor.

The cold air introduced from outside mixes with the hot air in the room and causes a considerable drop in indoor temperatures.

We conclude that in all three cases the ventilation affects indoor temperatures.

\subsection{Visibility distribution}

One of the most important parameters for evacuation in room fires is visibility. According to fire performance-based criterion, a minimum visibility of $10(\mathrm{~m})$ at one person's head must be maintained for evacuating and ensure the possibility for the fire fighters to put out the fire [15].

In the next figure (Fig. 8) the visibility decreases in the experiment (CASE1) below $2(m)$. In this situation, conditions for the evacuation of users can no longer be ensured. When the ventilation systems work (CASE1, CASE2, CASE3), the visibility increases at almost $5(\mathrm{~m})$ : evacuation conditions are provided even if in difficult conditions.

On average, the three fire ventilation systems offer similar performance. In the initial phase, mechanical ventilation offers better performance because the speed of natural circulation of hot air is slow at low temperatures. 


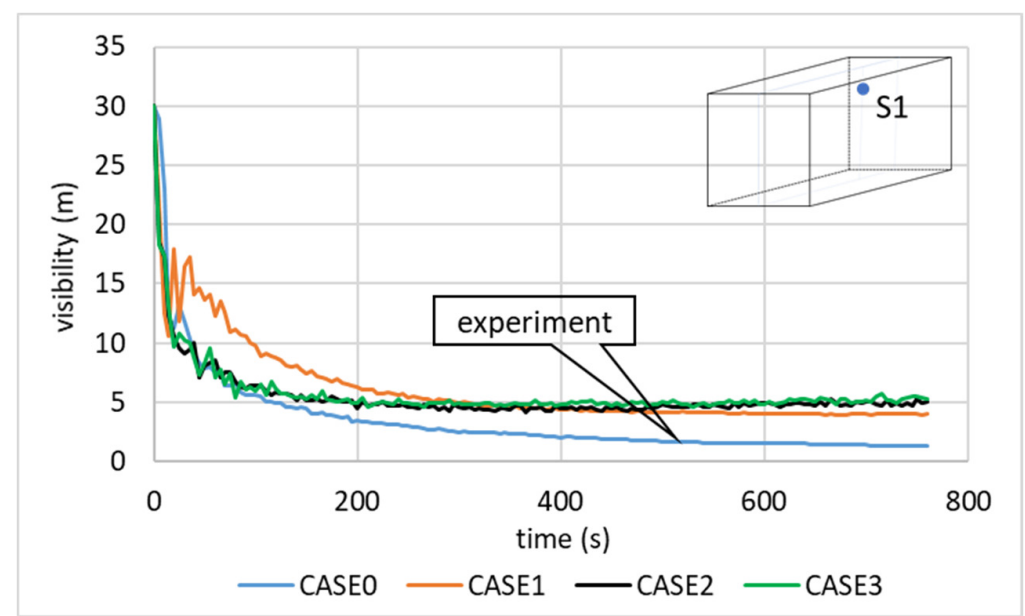

Fig. 8 Visibility evolution chart, point S1.

Fig. 9 shows that mechanical ventilation and natural ventilation considerably increase the visibility. No significant differences are observed in terms of natural ventilation performance between the two situations studied: CASE2- wall hatches and CASE3- roof hatches.
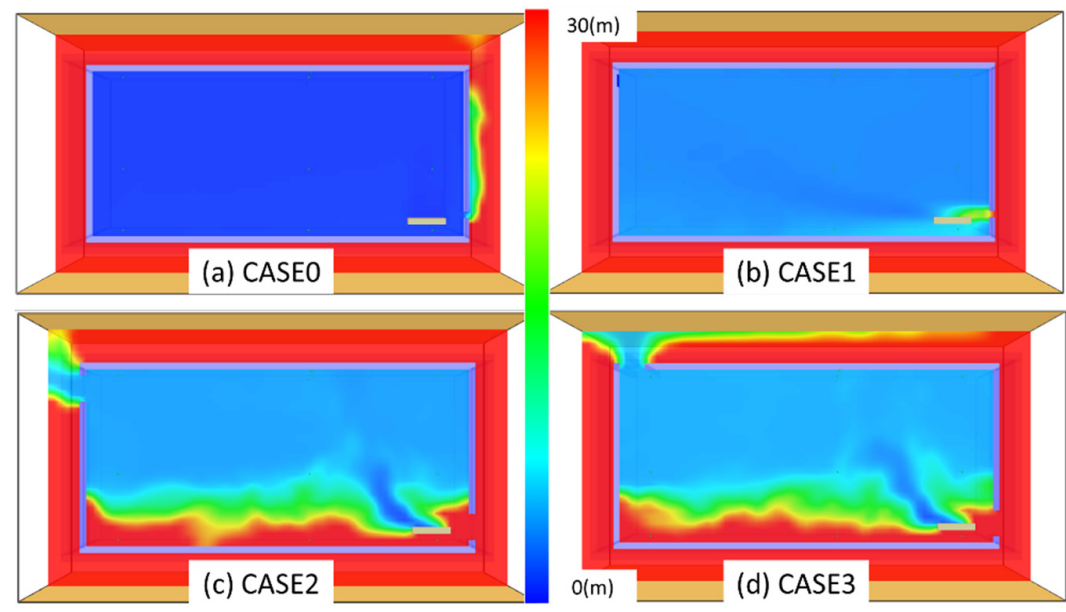

Fig. 9 Visibility at $\mathrm{t}=760(\mathrm{~s}), \mathrm{y}=2.1(\mathrm{~m})$

Visibility is higher at the bottom of the camera. When there is no ventilation system at the end of the experiment the visibility decreases to almost zero. When there is a ventilation system the visibility is maintained at approximately $5(\mathrm{~m})$ which means that parameters for evacuation are maintained but in difficult conditions.

\subsection{Oxygen concentration distribution}

The concentration of oxygen in the air is important because oxygen is indispensable for human survival, low oxygen concentrations leading to loss of consciousness and eventually death. During a fire, oxygen is used in the combustion 
Experimental and numerical study on the performance of different fire ventilation systems process resulting in carbon dioxide and other harmful gases depending on the type of fuel used.

LPG is a mixture of propane and butane. The chemical equations of combustion are given below [16]:

$$
\begin{aligned}
& \text { chemical propane combustion equation: } \mathrm{C}_{3} \mathrm{H}_{8}+5 \mathrm{O}_{2} \rightarrow 3 \mathrm{CO}_{2}+4 \mathrm{H}_{2} \mathrm{O}(2) \\
& \text { chemical butane combustion equation: } 4 \mathrm{C}_{4} \mathrm{H}_{10}+9 \mathrm{O}_{2} \rightarrow 8 \mathrm{CO}_{2}+10 \mathrm{H}_{2} \mathrm{O} \text { ( } 3 \text { ) }
\end{aligned}
$$

When no ventilation system is operating oxygen, concentration decreases rapidly (Fig. 10 ) under the value of $0.19(\mathrm{~mol} / \mathrm{mol})$. When the ventilation systems are working, the oxygen concentration is set at values higher than $0.202(\mathrm{~mol} / \mathrm{mol})$.

Mechanical ventilation provides better oxygen concentrations in the initial stages of the fire.

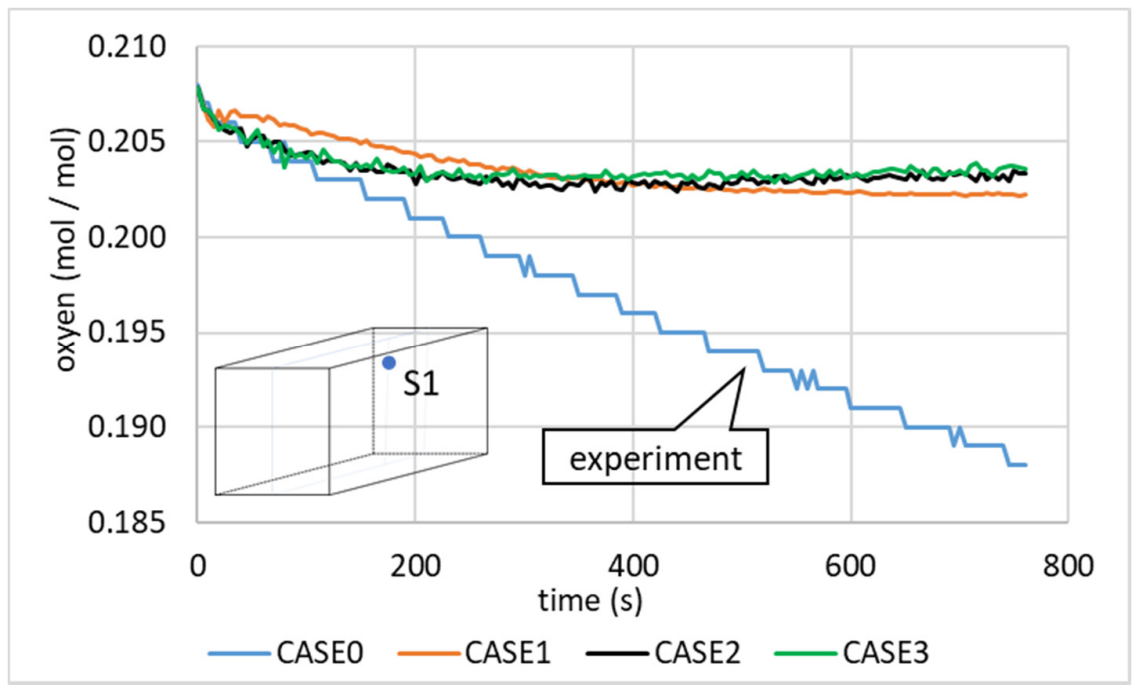

Fig. 10. Oxygen concentration evolution chart, point S1.

Fig. 11 shows that natural ventilation produces similar results in both cases studied (CASE2- wall hatches and CASE3- roof hatches). Mechanical ventilation produces greater agitation of the air and destratifies the air. At the bottom of the room the oxygen concentration is higher in all cases. 

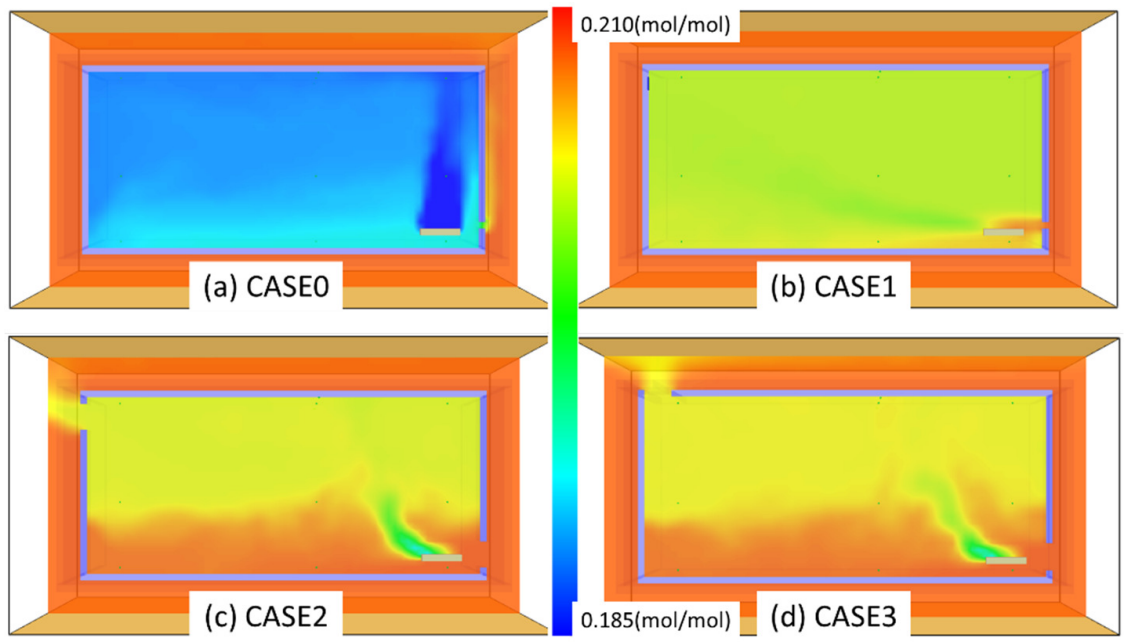

Fig. 11. Oxygen concentration at $t=760(\mathrm{~s}), y=2.10(\mathrm{~m})$

Analyzing the three parameters it can be concluded that a correct sizing makes both mechanical ventilation and natural ventilation to have close performance.

\section{Conclusions}

In this research, the performance of three ventilation system for the evacuation of smoke and hot air was compared.

A real-scale fire test has been performed on instrumented single room. During these test, temperatures have been recorded in sensor S1. This test have been used as reference test to validate fire-modeling tools. Mathematical modeling of the fire was performed using FDS.

The results obtained were compared with the experimental results recorded for the situation when there is no mechanical or natural ventilation system.

Three fire ventilation systems have been proposed and studied: mechanical ventilation (CASE1) and natural ventilation (CASE2- wall hatches and CASE3- roof hatches).

Based on the analysis of the temperature distribution, visibility distribution and oxygen concentration distribution, it can be concluded qualitatively that:

1. mechanical ventilation provides better performance in the early stages of the fire.

2. the stratification of hot air is more pronounced in the case of natural ventilation.

3. the increase in indoor temperature leads to an increase in the flow of hot air and smoke.

4. fire ventilation systems maintain low temperatures, good visibility, and high oxygen concentration, ensuring optimal conditions for the survival and evacuation of users.

5. FDS provides good results in fire modeling. 
Experimental and numerical study on the performance of different fire ventilation systems

6. natural or mechanical ventilation protects the building elements by cooling the air.

The main conclusion is that a well-sized ventilation system provides similar results regardless of whether it is mechanical or natural ventilation for the evacuation of smoke and hot air.

\section{Acknowledgment}

Author would like to thank Dr. Vlad Iordache for his valuable support and advice, Dr. Ilinca Năstase and all the technical staff of Department of Thermohydraulic Systems and for Atmoshere Protection involved in construction, instrumentation, and realization of the tests.

\section{References}

[1] Law 307/2006 on fire protection, Romania, 2006.

[2] P. Carlotti, D. Parisse, N. Rislera, Statistical analysis of intervention reports for fires resulting in casualties deceased on the spot in Paris area, Fire Safety Journal, 2017.

[3] H. Gormsen, N. Jeppesen, A. Lund, The causes of death in fire victims, 1984: Forensic Science International.

[4] S. Tavelli, R. Rota, M. Derudi, A Critical Comparison Between CFD and Zone Models for the Consequence Analysis of Fires in Congested Environments, Chemical Engineering Transactions, vol. 36, 2014.

[5] Kevin McGrattan, Bryan Klein, Simo Hostikka, Jason Floyd, Fire dynamics simulator 5 user guide, National Institute of Standards, 2019.

[6] R. Luiz, F. Oliveira, G. Doubek, S. S. V. Vianna, On the behaviour of the temperature field around pool fires in controlled experiment and numerical modelling, Process Safety and Environmental Protection, 2019.

[7] E. Guillaume, F. Didieux, A. Thiry, A. Bellivier, Real-scale fire tests of one bedroom apartments with regard to tenability assessment, Fire Safety Journal, 2014.

[8] EN 1991-1-2: Eurocode 1: Actions onstructures - Part 1-2: General actions - Actions onstructures exposed to fire, 2002.

[9] A. M. Salem, Parametric analysis of a cabin fire using a zone fire model, Alexandria Engineering Journal, 2013.

[10] Z. Xu, X.Z. Lu, H. Guan, C. Chen, A.Z. Ren, A virtual reality based fire training simulator with smoke hazard assessment capacity, Advances in Engineering Software, 2013.

[11] Y. Huang, E. Wang, Y. Bie, Simulation investigation on the smoke spread process in the largespace building with various height, Case Studies in Thermal Engineering, 2020.

[12] M. Lulea, V. Iordache, I. Năstase, Fire simulation by using three methods of introducing HRR (Heat Release Rate), Bucharest: Romanian Civil Engineering Magazine, 2019.

[13] SR 10903-2, Fire protection measures. Determination of the thermal load in constructions, ASRO, 2016.

[14] P118-Romanian building fire safety regulation, 1999.

[15] Yuang Jiang-Ping, Fang Zheng, Tang Zhi, Sun Jia-yun, Numerical simulations on sprinkler system and impulse ventilation in a underground car park, Wuhan: Engineering Procedia, 2011.

[16] B. Horbaniuc, G. Dumitraşcu, Procese de ardere, Editura POLITEHNIUM, 2008. 
Marius Dorin Lulea 